\title{
Factors associated with obstetric interventions in public maternity hospitals
}

Keli Regiane Tomeleri da Fonseca Pinto 1

https://orcid.org/0000-0003-1280-8421

Adriana Valongo Zani 2

iD https://orcid.org/0000-0002-6656-8155

Cátia Campaner Ferrari Bernardy 3

https://orcid.org/0000-0001-9723-1857

Mariana Angela Rossaneis 4

https://orcid.org/0000-0002-8607-0020

\author{
Renne Rodrigues 5 \\ iD https://orcid.org/0000-0003-1390-5901 \\ Cristina Maria Garcia de Lima Parada 6 \\ (iD) https://orcid.org/0000-0002-9597-3635
}

\footnotetext{
1,6 Faculdade de Medicina. Universidade Estadual Paulista Júlio de Mesquita Filho. Campus Botucatu. Av. Prof. Mário Rubens Guimarães Montenegro. s.n. Botucatu, SP, Brasil. CEP: 18.618-687.E mail: tomeleri@yahoo.com.br
}

2-5 Universidade Estadual de Londrina. Londrina, PR, Brasil.

\begin{abstract}
Objectives: to identify the prevalence and factors associated with obstetric interventions in parturients assisted in public maternity hospitals.

Methods: a cross-sectional study with 344 puerperal women, from two public maternity hospitals, referring to childbirth by Sistema Único de Saúde (SUS) (Public Health Service System) in Londrina City, Paraná, Brazil, between January and June 2017. The medical records were the data source. The following obstetric interventions were considered: oxytocin use, artificial rupture of the membranes, instrumental childbirth and episiotomy. Multivariate Poisson regression was used to analyze associated factors, with $p<5 \%$ being significant.

Results: the prevalence of obstetric intervention was 55.5\%, the maximum number of interventions in the same parturient woman was three. The most frequent interventions were the use of oxytocin (50.0\%) and artificial rupture of membranes $(29.7 \%)$. The variables associated on maternal disease $(p=0.005)$ and intrapartum meconium $(p=0.022)$ independently increased, the risk of obstetric intervention, while dilation was equal to or greater than $5 \mathrm{~cm}$ at admission, there was a protective factor against this outcome $(p=0.030)$.

Conclusion: the prevalence of obstetric interventions was high. In the case of maternal disease and intrapartum meconium, special attention should be given to the parturient woman, in order to avoid unnecessary interventions. Thus, the maternity hospitals need to review their protocols, seeking good practices in childbirth care.
\end{abstract}

Key words Natural childbirth, Labor, Medicalization, Maternal and child health

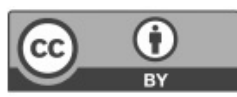




\section{Introduction}

Childbirth and birth care have been marked worldwide by the adoption of interventionist practices with the use of medications, technological devices and other procedures to accelerate or control the parturition process. Considering that childbirth is a physiological event, this care model is characterized as technocratic and medicalized. ${ }^{1}$

In the context of good birth-related practices, it is expected that any intervention to the natural and spontaneous process of labor and childbirth should have plausible justification for such, 2 because, although, the use of health technology contributes in reducing maternal and neonatal morbidity and mortality, its excessive and/or unnecessary use leads women and their newborns to health risks. ${ }^{3}$

Also in this context, recommendations for childbirth care have been based on humanized care, aiming to promote healthy deliveries and births, with the guarantee of women's protagonism and respecting their privacy and autonomy. ${ }^{4}$ However, these recommendations have proved insufficient, because, in some services, the scenario remains unchanged, with the use of unnecessary interventions and without scientific evidence. A study conducted in the South of Brazil identified several procedures harmful to labor and some were used inappropriately, such as fasting prescription, oxytocin use, amniotomy, episiotomy and delivery in the lithotomic position. ${ }^{2}$

It is noteworthy that, despite the decrease in the interventions over the years, due to health education actions, the situation remains far from ideal.Thus, other studies are necessary to identify new factors involved with its implementation, in order to continue changing the scenario consisting of routine and unnecessary interventions, without maternal consent and without the professional's consideration about the real benefits and consequences for the mother and child binomial, in order to contribute in overcoming the technical paradigm. Considering the importance of health services evaluating the developed obstetric care, this study aims to identify the prevalence and factors associated with obstetric interventions in parturients assisted in public maternity hospitals.

\section{Methods}

This cross-sectional study was carried out in two referring public maternity hospitals for childbirths by the Sistema Único de Saúde (SUS) (Public Health Service System) in Londrina city, Paraná, Brazil.
Altogether, these maternities were responsible for $78.3 \%$ of the normal childbirths and $47.6 \%$ was all the deliveries in this city in 2017.5 This study integrates a broad research project entitled: Avaliação da atenção ao parto normal em maternidades públicas de um município da região sul do Brasil (Evaluation of normal childbirth care in public maternity hospitals in a city in the South of Brazil).

Data collection was performed between January and June 2017, using an instrument elaborated specifically for this study, the information was filled from the participating parturients' medical records contained in the hospital.

Women who had in-hospital vaginal delivery were considered eligible for the study. Exclusion criteria were: unfavorable clinical condition, due to severe complication of pregnancy and/or childbirth, which prevented the puerperal women from participating in the interview.

Considering the error margin of $5 \%$ in the research, the confidence level of $95 \%$ and 2,470 normal childbirths that occurred in 2015 in the two maternity hospitals for the study, the sample size was calculated as a finite population, based on the following equation: $\mathrm{n}=\mathrm{N} \cdot \mathrm{n}_{0} / \mathrm{N}+\mathrm{n}_{0}$, where $\mathrm{n}_{0}=1 / \mathrm{E} 0^{2}$, E0 being the tolerable sample error, which resulted in 344 participants.

From the beginning of the data collection, the women were consecutively selected by the interviewers, who were nursing undergraduate students and previously trained, with visits on alternated days to the maternity hospitals, until they achieved the sampled number.

The following variables were included in the study: sociodemographic variables: age group in years $(10-19,20-34,35$ or more), schooling in years $(<8, \geq 8)$, marital status (with a partner, without a partner) and paying job (yes, no); previous obstetric variables: parity (primigravidae, multigravidae), previous abortion (yes, no) and previous cesarean section (yes, no); prenatal: prenatal care (yes, no), number of prenatal consultations $(<6, \geq 6)$; related to pre-partum and delivery: cervical dilation in centimeters $(<5, \geq 5)$, uterine dynamics (yes, no), membrane status (intact, routes), associated disease (yes, no) and intrapartum meconium (yes, no) and about the newborn: gestational age at birth in weeks $(<37, \geq 37)$ and weight in grams $(\geq 2500,<2500)$.

The outcome variable was obstetric intervention performed during labor and childbirth, defined in this study as the use of at least one of the following practices: use of oxytocin; artificial rupture of membranes; instrumental delivery (forceps or vacuum extractor) and episiotomy. 
The analyses were performed with the Statistical Package for the Social Sciences (SPSS) software 22.0. Initially, a description of the characteristics of the participants was performed. To evaluate possible factors associated with obstetric interventions, Poisson regression with prevalence ratio (PR) was used as a measure of model association. Initially, a bivariate analysis was carried out between the independent variables (sociodemographic, obstetric, prenatal, hospitalization and newborn) and dependent variables (obstetric intervention). Those with $p<0.20$ remained in the multivariate analysis. To make up the final model, the level of significance adopted was $p<0.05$. For all the analyses, a reference category was established, considered the one with the lowest risk for the occurrence of the outcome.

The project of this research was approved by the Research Ethics Committee, under the Certificate of Presentation for Ethical Appreciation (CAAE) n.57408616.0.0000.5231, complying with the formal requirements of regulatory standards for researches involving human beings. All interviewees and guardians, in case of underage participants, signed the Informed Consent Form (ICF).

\section{Results}

A total of 356 women were invited to participate in the study, but 12 refused to participate, thus completing the expected sample of 344 participants. Of these, 171 had obstetric intervention, a prevalence of $55.5 \%$, with three as the maximum number of interventions in the same woman. Of the 248 interventions performed, the use of oxytocin and artificial rupture of membranes were the most frequent, with rates of $50.0 \%$ and $29.7 \%$, respectively; episiotomy $(7.8 \%)$ and instrumental delivery, by forceps or vacuum extractor $(0.6 \%)$ were the least frequent.

Most participants were between 20 and 34 years old $(72.6 \%)$ and had eight or more years of schooling $(82.6 \%)$; had a partner $(90.7 \%)$ and had no paying job $(63.1 \%)$; regarding obstetric characteristics, the majority was multigravidae (75.6\%). Almost all reported having had prenatal care $(98.2 \%)$ and births were full-term $(96.2 \%)$. At admission, the majority had cervical dilation below $5 \mathrm{~cm}(60.8 \%)$ and presence of uterine dynamics (67.7\%) (Table 1).

Regarding the bivariate analysis, the following variables were included in the multivariate model: years of schooling $(\mathrm{PR}=0.55$; CI95\% $=0.35-0.85)$, marital status $(\mathrm{PR}=1.38$; $\mathrm{CI} 95 \%=1.01-1.89)$, parity $(\mathrm{PR}=1.21$; CI95\%=0.96-1.54), previous abortion $(\mathrm{PR}=.63$; CI95\%=0.99-2.67), number of prenatal consultations $(\mathrm{PR}=1.24 ; \mathrm{CI} 95 \%=0.94-1.63)$, cervical dilation $(\mathrm{PR}=0.77 ; \quad \mathrm{CI} 95 \%=0.60-0.98)$, uterine dynamics $(\mathrm{PR}=0.76$; CI95\% $=0.56-1.03)$, membrane status $(\mathrm{PR}=0.78 ; \mathrm{CI} 95 \%=0.56-1.09)$, associated maternal disease $(\mathrm{PR}=1.39$; $\mathrm{CI} 95 \%=1.08-1.79)$, gestational age $(\mathrm{PR}=0.33 ; \mathrm{CI} 95 \%=0.09-1.21)$, newborn weight $(\mathrm{PR}=0.47$; $\mathrm{CI} 95 \%=0.17-1.30)$ and intrapartum meconium $(\mathrm{PR}=1.34$; CI95\% $=0.93$ 1.92) (Table 2). The variables lithotomic position and companion at childbirth, however, were not included in the model because they presented frequencies close to $100 \%$.

After adjustments, independently, the variables on maternal disease $(\mathrm{PR}=1.60, \mathrm{CI} 95 \%=1.15-2.24$, $p=0.005)$ and intrapartum meconium $(\mathrm{PR}=1.55$, $\mathrm{CI} 95 \%=1.06-2.27, p=0.022)$ presented increased risk of obstetric intervention. On the other hand, the presence of dilation greater than or equal to $5 \mathrm{~cm}$ at admission $(\mathrm{PR}=0.72$, CI95\% $=0.54-0.97, p=0.030)$ proved to be a protective factor for this outcome (Table 3).

\section{Discussion}

This study identified a high prevalence of obstetric interventions, especially in the use of oxytocin and the artificial rupture of membranes in women assisted in the public maternity hospitals. Independently, in the presence of maternal disease and intrapartum meconium, obstetric interventions were more frequent, while hospitalization with dilation equal to or greater than $5 \mathrm{~cm}$ protected the parturients against this outcome.

The presence of intrapartum meconium has been the focus of researches worldwide. In Ethiopia, a study with 495 women identified that those who received oxytocin for childbirth induction had a 2.6 times higher chance of the presence of meconium in the amniotic fluid when compared to women in labor without induction. ${ }^{6}$ A retrospective cohort conducted in Israel found a negative impact on perinatal outcome in the presence of meconium amniotic fluid, even at term and low-risk pregnancies. ${ }^{7} \mathrm{~A}$ comprehensive review study on the presence of meconium in the amniotic fluid pointed out the relevance of preventing oxytocin misuse in order to avoid adverse perinatal outcomes. ${ }^{8}$

The relevance of the presence of intrapartum meconium is that it is a necessary condition for the occurrence of meconium aspiration syndrome, which reflects a wide spectrum of disorders, ranging from mild tachypnea to severe respiratory distress, with high perinatal mortality. ${ }^{9}$ In the present study, the presence of meconium was identified in intrapartum 
Table 1

Sociodemographic, obstetric characterization, related to prenatal care, hospitalization, childbirth and newborn of women who had a normal delivery in two public maternity hospitals in Londrina/PR, 2017.

\begin{tabular}{|c|c|c|}
\hline Variables & $\mathbf{N}$ & $\%$ \\
\hline \multicolumn{3}{|l|}{ Age group (years) } \\
\hline $10-19$ & 68 & 19.8 \\
\hline $20-34$ & 250 & 72.6 \\
\hline$\geq 35$ & 26 & 7.6 \\
\hline \multicolumn{3}{|l|}{ Schooling (years) } \\
\hline$<8$ & 59 & 17.4 \\
\hline$\geq 8$ & 285 & 82.6 \\
\hline \multicolumn{3}{|l|}{ Marital status } \\
\hline With a partner & 312 & 90.7 \\
\hline Without a partner & 32 & 9.3 \\
\hline \multicolumn{3}{|l|}{ Paying job } \\
\hline Yes & 127 & 36.9 \\
\hline No & 217 & 63.1 \\
\hline \multicolumn{3}{|l|}{ Parity } \\
\hline Primigravidae & 84 & 24.4 \\
\hline Multigravidae & 260 & 75.6 \\
\hline \multicolumn{3}{|l|}{ Previous abortion } \\
\hline Yes & 42 & 12.2 \\
\hline No & 302 & 87.8 \\
\hline \multicolumn{3}{|c|}{ Previous Cesarean section } \\
\hline Yes & 32 & 9.3 \\
\hline No & 312 & 90.7 \\
\hline \multicolumn{3}{|l|}{ Prenatal } \\
\hline Yes & 338 & 98.2 \\
\hline No & 6 & 1.8 \\
\hline \multicolumn{3}{|c|}{ Number of prenatal visits* } \\
\hline$\leq 5$ & 57 & 16.7 \\
\hline$\geq 6$ & 287 & 83.3 \\
\hline \multicolumn{3}{|c|}{ Cervical dilation at admission $(\mathrm{cm})$ * } \\
\hline$<5$ & 203 & 60.8 \\
\hline$\geq 5$ & 131 & 39.2 \\
\hline \multicolumn{3}{|c|}{ Uterine dynamics at admission } \\
\hline Yes & 248 & 67.7 \\
\hline No & 96 & 32.3 \\
\hline \multicolumn{3}{|c|}{ State of membranes at admission } \\
\hline Whole & 270 & 73.6 \\
\hline Damaged & 74 & 26.4 \\
\hline \multicolumn{3}{|l|}{ Maternal disease** } \\
\hline Yes & 66 & 19.2 \\
\hline No & 278 & 80.8 \\
\hline \multicolumn{3}{|c|}{ Gestational age (weeks) } \\
\hline$<37$ & 13 & 3.8 \\
\hline$\geq 37$ & 331 & 96.2 \\
\hline \multicolumn{3}{|c|}{ Presence of companion at childbirth } \\
\hline Yes & 320 & 93.0 \\
\hline No & 24 & 7.0 \\
\hline
\end{tabular}

*The sample varied due to the lack of information in the medical record; ** Includes: syphilis, hypothyroidism, obesity, gestational diabetes, gestational hypertension and depression. 
Sociodemographic, obstetric characterization, related to prenatal care, hospitalization, childbirth and newborn of women who had a normal delivery in two public maternity hospitals in Londrina/PR, 2017.

\begin{tabular}{lcc}
\hline Variables & N & $\%$ \\
\hline Delivery position & & 97.4 \\
$\quad$ Lithotomic & 335 & 2.6 \\
$\quad$ Non-lithotomic & 9 & \\
Newborn's weight (g) & 14 & 4.1 \\
$\quad \leq 2499$ & 330 & 95.9 \\
$\geq 2500$ & & 7.0 \\
Intrapartum meconium & 24 & 93.0 \\
$\quad$ Yes & 320 & \\
No & & \\
\hline
\end{tabular}

*The sample varied due to the lack of information in the medical record; ** Includes: syphilis, hypothyroidism, obesity, gestational diabetes, gestational hypertension and depression.

\section{Tabela 2}

Bivariate analysis between obstetric intervention and sociodemographic, obstetric, prenatal, hospitalization and newborn variables of women who had a normal delivery in two public maternity hospitals in Londrina/PR, 2017.

\begin{tabular}{|c|c|c|c|c|c|c|}
\hline \multirow[t]{3}{*}{ Variables } & \multicolumn{6}{|c|}{ Obstetric Intervention } \\
\hline & \multicolumn{2}{|c|}{ No } & \multicolumn{2}{|c|}{ Yes } & \multirow[t]{2}{*}{ PR $(\mathrm{Cl} 95 \%)$} & \multirow[t]{2}{*}{$p$} \\
\hline & $\mathrm{n}$ & $\%$ & $\mathrm{n}$ & $\%$ & & \\
\hline \multicolumn{7}{|l|}{ Age group (years) } \\
\hline $20-34$ & 113 & 45.2 & 137 & 54.8 & 1.00 & \\
\hline $10-19$ & 31 & 45.6 & 37 & 54.4 & $1.00(0.75-1.35)$ & 0.954 \\
\hline$\geq 35$ & 9 & 34.6 & 17 & 65.4 & $0.76(0.44-1.32)$ & 0.338 \\
\hline \multicolumn{7}{|l|}{ Schooling (years) } \\
\hline$\geq 8$ & 137 & 48.2 & 147 & 51.8 & 1.00 & \\
\hline$<8$ & 16 & 26.7 & 44 & 73.3 & $0.55(0.35-0.85)$ & 0.008 \\
\hline \multicolumn{7}{|l|}{ Marital status } \\
\hline With a partner & 134 & 42.9 & 178 & 57.1 & 1.00 & \\
\hline Without a partner & 19 & 59.4 & 13 & 40.6 & $1.38(1.01-1.89)$ & 0.043 \\
\hline \multicolumn{7}{|l|}{ Paying job } \\
\hline Yes & 59 & 46.5 & 68 & 53.5 & 1.00 & \\
\hline No & 94 & 43.3 & 123 & 56.7 & $0.93(0.73-1.18)$ & 0.569 \\
\hline \multicolumn{7}{|l|}{ Parity } \\
\hline Primigravidae & 107 & 41.1 & 153 & 58.9 & 1.00 & \\
\hline Multigravidae & 42 & 50.0 & 42 & 50.0 & $1.21(0.96-1.54)$ & 0.099 \\
\hline \multicolumn{7}{|l|}{ Previous abortion } \\
\hline Yes & 141 & 46.7 & 161 & 53.3 & 1.00 & \\
\hline No & 12 & 28.6 & 30 & 71.4 & $1.63(0.99-2.67)$ & 0.051 \\
\hline \multicolumn{7}{|c|}{ Previous Cesarean section } \\
\hline Yes & 140 & 44.9 & 172 & 55.1 & 1.00 & \\
\hline No & 13 & 40.6 & 19 & 59.4 & $0.90(0.58-1.40)$ & 0.655 \\
\hline \multicolumn{7}{|l|}{ Prenatal } \\
\hline Yes & 150 & 44.4 & 188 & 55.6 & 1.00 & \\
\hline No & 3 & 50.0 & 3 & 50.0 & $1.12(0.49-2.51)$ & 0.784 \\
\hline
\end{tabular}

*The sample varied due to the lack of information in the medical record; ** Includes: syphilis, hypothyroidism, obesity, gestational diabetes, gestational hypertension and depression. 
Bivariate analysis between obstetric intervention and sociodemographic, obstetric, prenatal, hospitalization and newborn variables of women who had a normal delivery in two public maternity hospitals in Londrina/PR, 2017.

\begin{tabular}{|c|c|c|c|c|c|c|}
\hline \multirow[t]{3}{*}{ Variables } & \multicolumn{6}{|c|}{ Obstetric Intervention } \\
\hline & \multicolumn{2}{|c|}{ No } & \multicolumn{2}{|c|}{ Yes } & \multirow[t]{2}{*}{ PR $(\mathrm{Cl} 95 \%)$} & \multirow[t]{2}{*}{$p$} \\
\hline & $\mathrm{n}$ & $\%$ & $\mathrm{n}$ & $\%$ & & \\
\hline \multicolumn{7}{|c|}{ Number of prenatal visits* } \\
\hline$\leq 5$ & 122 & 42.9 & 164 & 57.1 & 1.00 & \\
\hline$\geq 6$ & 31 & 53.4 & 27 & 46.6 & $1.24(0.94-1.63)$ & 0.119 \\
\hline \multicolumn{7}{|c|}{ Cervical dilation at admission $(\mathrm{cm})$ * } \\
\hline$<5$ & 66 & 50.4 & 65 & 49.6 & 1.00 & \\
\hline$\geq 5$ & 79 & 38.9 & 124 & 61.1 & $0.77(0.60-0.98)$ & 0.037 \\
\hline \multicolumn{7}{|c|}{ Uterine dynamics at admission } \\
\hline Yes & 106 & 42.8 & 142 & 57.2 & 1.00 & \\
\hline No & 35 & 36.5 & 61 & 63.5 & $0.76(0.56-1.03)$ & 0.079 \\
\hline \multicolumn{7}{|c|}{ State of membranes at admission } \\
\hline Whole & 116 & 43.0 & 154 & 57.0 & 1.00 & \\
\hline Damaged & 27 & 36.5 & 47 & 63.5 & $0.78(0.56-1.09)$ & 0.151 \\
\hline \multicolumn{7}{|c|}{ Maternal disease** } \\
\hline Yes & 114 & 41.1 & 164 & 58.9 & 1.00 & \\
\hline No & 38 & 57.6 & 28 & 42.4 & $1.39(1.08-1.79)$ & 0.009 \\
\hline \multicolumn{7}{|c|}{ Gestational age (weeks) } \\
\hline$\geq 37$ & 151 & 45.6 & 180 & 54.4 & 1.00 & \\
\hline$<37$ & 2 & 15.4 & 11 & 84.6 & $0.33(0.09-1.21)$ & 0.096 \\
\hline \multicolumn{7}{|c|}{ Newborn's weight (grams) } \\
\hline$\geq 2500$ & 150 & 45.5 & 180 & 54.5 & 1.00 & \\
\hline$\leq 2499$ & 3 & 21.4 & 11 & 78.6 & $0.47(0.17-1.30)$ & 0.148 \\
\hline \multicolumn{7}{|c|}{ Intrapartum meconium } \\
\hline No & 139 & 43.4 & 181 & 56.6 & 1.00 & \\
\hline Yes & 14 & 58.3 & 10 & 41.7 & $1.34(0.93-1.92)$ & 0.109 \\
\hline
\end{tabular}

*The sample varied due to the lack of information in the medical record; ** Includes: syphilis, hypothyroidism, obesity, gestational diabetes, gestational hypertension and depression.

Table 3

Multivariate analysis of sociodemographic and obstetric variables related to prenatal care, hospitalization and newborns of women who had a normal delivery in two public maternity hospitals in Londrina/PR, 2017.

\begin{tabular}{|c|c|c|c|c|c|c|}
\hline \multirow[t]{3}{*}{ Variables } & \multicolumn{6}{|c|}{ Obstetric Intervention } \\
\hline & \multicolumn{2}{|c|}{ No } & \multicolumn{2}{|c|}{ Yes } & \multirow[t]{2}{*}{ PR (CI95\%) } & \multirow[t]{2}{*}{$p$} \\
\hline & $\mathrm{n}$ & $\%$ & $n$ & $\%$ & & \\
\hline \multicolumn{7}{|l|}{ Schooling (years) } \\
\hline$\geq 8$ & 137 & 48.2 & 147 & 51.8 & 1.00 & \\
\hline$<8$ & 16 & 26.7 & 44 & 73.3 & $0.63(0.38-1.05)$ & 0.076 \\
\hline \multicolumn{7}{|l|}{ Marital status } \\
\hline With a partner & 134 & 42.9 & 178 & 57.1 & 1.00 & \\
\hline Without a partner & 19 & 59.4 & 13 & 40.6 & $1.22(0.81-1.83)$ & 0.328 \\
\hline \multicolumn{7}{|l|}{ Parity } \\
\hline Multigravidae & 107 & 41.1 & 153 & 58.9 & 1.00 & \\
\hline Primigravidae & 42 & 50.0 & 42 & 50.0 & $0.96(0.70-1.32)$ & 0.841 \\
\hline
\end{tabular}

* The sample varied due to the lack of information in the medical record; ** Includes: syphilis, hypothyroidism, obesity, gestational diabetes, gestational hypertension and depression. 
Multivariate analysis of sociodemographic and obstetric variables related to prenatal care, hospitalization and newborns of women who had a normal delivery in two public maternity hospitals in Londrina/PR, 2017.

\begin{tabular}{|c|c|c|c|c|c|c|}
\hline \multirow[t]{3}{*}{ Variables } & \multicolumn{6}{|c|}{ Obstetric Intervention } \\
\hline & \multicolumn{2}{|c|}{ No } & \multicolumn{2}{|c|}{ Yes } & \multirow[t]{2}{*}{ PR $(\mathrm{Cl} 95 \%)$} & \multirow[t]{2}{*}{$p$} \\
\hline & $\mathrm{n}$ & $\%$ & $\mathrm{n}$ & $\%$ & & \\
\hline \multicolumn{7}{|c|}{ Previous abortion } \\
\hline No & 141 & 46.7 & 161 & 53.3 & 1.00 & \\
\hline Yes & 12 & 28.6 & 30 & 71.4 & $1.61(0.94-2.74)$ & 0.078 \\
\hline \multicolumn{7}{|c|}{ Number of prenatal visits } \\
\hline$\geq 6$ & 122 & 42.9 & 164 & 57.1 & 1.00 & \\
\hline$\leq 5$ & 31 & 53.4 & 27 & 46.6 & $1.20(0.88-1.64)$ & 0.228 \\
\hline \multicolumn{7}{|c|}{ Cervical dilation at admission $(\mathrm{cm})$ * } \\
\hline$\geq 5$ & 66 & 50.4 & 65 & 49.6 & 1.00 & \\
\hline$<5$ & 79 & 38.9 & 124 & 61.1 & $0.72(0.54-0.97)$ & 0.030 \\
\hline \multicolumn{7}{|c|}{ Uterine dynamics at admission } \\
\hline Yes & 106 & 42.8 & 142 & 57.2 & 1.00 & \\
\hline No & 35 & 36.5 & 61 & 63.5 & $0.70(0.50-1.00)$ & 0.050 \\
\hline \multicolumn{7}{|c|}{ State of membranes at admission } \\
\hline Whole & 116 & 43.0 & 154 & 57.0 & 1.00 & \\
\hline Damaged & 27 & 36.5 & 47 & 63.5 & $1.04(0.75-1.44)$ & 0.798 \\
\hline \multicolumn{7}{|c|}{ Maternal disease** } \\
\hline Yes & 114 & 41.1 & 164 & 58.9 & 1.00 & \\
\hline No & 38 & 57.6 & 28 & 42.4 & $1.60(1.15-2.24)$ & 0.005 \\
\hline \multicolumn{7}{|c|}{ Gestational age (weeks) } \\
\hline$\geq 37$ & 151 & 45.6 & 180 & 54.4 & 1.00 & \\
\hline$<37$ & 2 & 15.4 & 11 & 84.6 & $0.98(0.22-4.21)$ & 0.980 \\
\hline \multicolumn{7}{|c|}{ Newborn's weight (grams) } \\
\hline$\geq 2500$ & 150 & 45.5 & 182 & 54.5 & 1.00 & \\
\hline$\leq 2499$ & 3 & 21.4 & 11 & 78.6 & $0.57(0.19-1.72)$ & 0.326 \\
\hline \multicolumn{7}{|c|}{ Intrapartum meconium } \\
\hline No & 139 & 43.4 & 181 & 56.6 & 1.00 & \\
\hline Yes & 14 & 58.3 & 10 & 41.7 & $1.55(1.06-2.27)$ & 0.022 \\
\hline
\end{tabular}

* The sample varied due to the lack of information in the medical record; ** Includes: syphilis, hypothyroidism, obesity, gestational diabetes, gestational hypertension and depression.

and, thus, after the use of oxytocin in labor. Thus, in the condition in which this intervention is necessary, monitoring should be careful, even in the expulsive period, in order to prevent aspiration and, consequently, interference in the normal transition to extrauterine life.

There are studies that report higher rates of interventions in more complex services 10 where, in general, high-risk deliveries occur. In Australia, a study with 5,840 women, which examined the role of modifiable and non-modifiable factors that promote or inhibit normal delivery and estimated the probability of normal delivery without intervention, found an association between maternal disease and childbirth intervention. 11 A possible explanatory hypothesis for using interventions in the condition of maternal disease, especially oxytocin, is related to the acceleration of the progression of labor. ${ }^{12}$

Concerning the reduction in the labor duration, evidence indicates that no clinical intervention should be offered during the first and second stages, including amniotomy and oxytocin supply, even when epidural analgesia is performed, if labor progresses normally, the woman and baby are well. 3,13

A study addressing the interruption of oxytocin use after the establishment of the active phase of labor found a reduction in the cesarean rate, but recommended interpreting this result with caution, due to the possibility of bias in the included studies. 14 It is emphasized that cesarean section should be performed only when clinically necessary, 
or a vaginal delivery represents a risk to the mother and child's health and in the appearance of complications such as fetal distress, abnormal fetal presentation, pre-partum hemorrhage and hypertensive disease. 15,16

An important finding of the present study was that hospitalizing the parturient with cervical dilation equal to or greater than $5 \mathrm{~cm}$ protected her from the use of obstetric intervention. On the contrary, early admission, before the active phase, increases the risk of obstetric interventions, including the use of oxytocin, 17 frequent intervention, present in half of the cases of this study. For the above, the results of the present study support the decision of hospitalization for delivery in the active phase of labor, in order to avoid unnecessary and iatrogenic interventions.

Although the prevalence of the set of interventions $(55.5 \%)$ was high, its occurrence was much lower than that found in a Brazilian national-sized research in the public and private services, which found $94.4 \%$ of obstetric interventions. 4 Nevertheless, this comparison needs to be carefully analyzed, since the aforementioned study considered a wider range of obstetric interventions: use of venous catheter, oxytocin to accelerate labor, amniotomy, spinal/epidural anesthesia, lithotomic position for delivery, Kristeller maneuver, episiotomy and cesarean operation. Considering only the use of oxytocin, the prevalence was higher in the present study $(50.0 \%$ vs $36.4 \%)$, while the reverse occurred with amniotomy $(29.7 \%$ vs $39.1 \%)$. Two other Brazilian studies found use of oxytocin in $42.7 \%$ of the surveyed women, 18 in a hospital in Goiânia and in a maternity hospital in Pernambuco, the rate of oxytocin was $41.0 \%$ and amniotomy rate of $31.0 \% .19$

The evidence indicates that amniotomy is a recommended practice when progression stops occurring and should not be performed without adequate control, with the aim of only advancing labor. ${ }^{20}$

Oxytocin is generally used to induce, accelerate or correct changes in the evolution of labor. ${ }^{21}$ Its use in the dilation period should be restricted to the correction of uterine dynamics in cases of failure in the progression of labor. 22 A literature review study pointed out that artificial stimulation of labor has a varied dimension, with the estimated $6.0 \%$ of the deliveries in developing countries and $20.0 \%$ in the United Kingdom. Despite being among the most common interventions in obstetrics, it is not riskfree, and, after induction, approximately $15 \%$ of the women will have instrumental delivery and $20 \%$ will progress to emergency cesarean section. ${ }^{23}$ In this sense, the rate in using oxytocin found in the two maternity hospitals in this study is considered high and as this is a modifiable practice, health services are responsible for promoting the review of their protocols, in order to avoid unnecessary risks, resulting from the use without precise indication.

The episiotomy rate found here is below the $10 \%$ accepted by the World Health Organization. ${ }^{24}$ In the national literature, a study with a lower prevalence $(2.0 \%)^{19}$ and another with higher prevalence was found, close to $50 \% .25$ The Nascer no Brasil (Born in Brazil) survey, was relevant due to its national scope, and which had a sample of 23,894 women, found episiotomy in $56 \%$ of vaginal deliveries. ${ }^{4}$ Thus, the situation obtained is more favorable than that of the country as a whole, indicating that the recommendation of routine use of this practice is being abolished in the services where the study was conducted.

Episiotomy is related to the presence of numerous local signs and symptoms, such as pain, bleeding, ecchymosis, hematoma, infection and dehiscence, besides being associated with dyspareunia, rectal fistula and psychic aspects, such as difficulties in breastfeeding, sexual dissatisfaction of women and partners and feeling of negative experience at childbirth. 26 A systematic review of the literature found that medical professionals perform episiotomy because they feel unsafe before the possibility of laceration of the birth canal.26

Operative vaginal delivery, by forceps or vacuum-extraction, should be performed in women who remain in prolonged expulsive period, with complete dilation and who present acute fetal distress. 27

A study conducted in India, which followed 5,445 childbirths, found a prevalence of operative vaginal delivery of $7.7 \%, 28$ another study conducted at a University Medical Center in Ethiopia with 242 women found a prevalence of $10.3 \%,{ }^{29}$ values much higher than in this study $(0.6 \%)$.

In summary, considering the results obtained, in the presence of maternal disease and intrapartum meconium, special attention should be given to the parturient, in order to avoid unnecessary interventions.

This study is limited because its data collection depended on the registration of professionals in the hospital. Thus, it is possible that the prevalence of reported interventions is somewhat underestimated, due to the absence of registration. Although, the study took place in two maternity hospitals, the results can be applied to other maternity hospitals 
with similar characteristics, i.e. a teaching hospital, a field of practice for obstetrics teaching.

Although the interventions presented a lower prevalence than that found in other national studies, the practice at the maternity hospitals in this study is far from good practices of caring in labor and childbirth, since pregnancy and birth physiological processes require few interventions. Thus, these services need to review their protocols on care, basing them on scientific evidence.

The findings obtained bring contributions to health services and professionals working in childbirth care, supporting the development and implementation of actions aimed to reduce unnecessary interventions and encourage good practices on childbirth care.

\section{References}

1. Vargens OMC, Silva ACV, Progianti JM. Contribuição de enfermeiras obstétricas para consolidação do parto humanizado em maternidades no Rio de Janeiro-Brasil. Esc Anna Nery. 2017; 21(1): e20170015.

2. Monteshio LVC, Sgobero JCG, Oliveira RR, Serafim D, Mathias TAF. Prevalência da medicalização do trabalho de parto e parto na rede pública de saúde. Ciênc Cuid Saúde. 2016; 15 (4): 591-8

3. Miller S, Abalos E, Chamillard M, Ciapponi A, Colaci D, Comandé D, Diaz V, Geller S, Hanson C, Langer A, Manuelli V, Millar K, Morhason-Bello I, Castro CP, Pileggi VN, Robinson N, Skaer M, Souza JP, Vogel JP, Althabe F. Beyond too little, too late and too much, too soon: a pathway towards evidence-based, respectful maternity care worldwide. Lancet. 2016; 288 (10056): 2176-92.

4. Leal MC, Pereira APE, Domingues RMSM, Filha MMT, Dias MAB, Pereira MN, Bastos MH, Gama SGN. Obstetric interventions during labour and birth in Brazilian low risk women. Cad Saúde Publica. 2014; 30 (Supl. 1): S1-S31.

5. Brasil. Ministério da Saúde. DATASUS. Informações em Saúde. Nascimento por residência da mãe/Tipo de parto/Município. Brasília, DF; 2017.

6. Addisu D, Asres A, Gedefaw G, Asmer S. Prevalence of meconium stained amniotic fluid and its associated factors among women who gave birth at term in Felege Hiwot comprehensive specialized referral hospital, North West Ethiopia: a facility based cross-sectional study. BMC Pregnancy Childbirth. 2018; 18: 429.

7. Hiersch L, Krispin E, Aviram A, Wiznitzer A, Yogev Y, Ashwal E. Effect of meconium amniotic fluid on perinatal complications in low-risk term pregnancies. Am J Perinatol. 2016; 33 (4): 378-84.

8. Mitchell S, Chandraharan E. Meconium-stained amniotic fluid. Obstet Gynaecol Reprod Med. 2018; 28 (4): 120-4

9. Vain NE, Batton DG. Meconium “aspiration” (or respiratory distress associated with meconium-stained amniotic fluid?). Semin Fetal Neonatal Med. 2017; 2 (4): 214-9.

\section{Authors' contribution}

Pinto KRTF, Zani AV, Bernardy CCF and Parada CMGL contributed to the conception of the article. Pinto KRTF collected the data. Rodrigues $\mathrm{R}$ and Rossaneis MA performed the statistical analysis. All authors approved the final version of the manuscript and are publicly responsible for the content of the article.

10. Pueyo M-J, Escuriet R, Perez-Botella M, Molina I, RuízBerdun D, Albert S, Díaz S, Torres-Capcha P, Ortún V. Health policies for the reduction of obstetric interventions in singleton full-term births in Catalonia. Health Policy. 2018; 122 (4): 367-72.

11. Prosser SJ, Barnett A, Miller YD. Factors promoting or inhibiting normal birth. BMC Pregnancy Childbirth. 2018; 18: 241 .

12. Santos IS, Okazaki ELFJ. Assistência de enfermagem ao parto humanizado. Rev Enferm UNISA. 2012; 13 (1): 64-8.

13. Uvnäs-Moberg K, Ekström-Bergström A, Berg M, Buckley S, Pajalic Z, Hadjigeorgiou E, Kotlowka A, Lengler L, Kielbratowska B, Leon-Larios F, Magistretti CM, Downe S, Lindstrom B, Dencker A. Maternal plasma levels of oxytocin during physiological childbirth - a systematic review with implications for uterine contractions and central actions of oxytocin. BMC Pregnancy Childbirth. $2019 ; 19: 285$.

14. Boie S, Glavind J, Velu AV, Mol BWJ, Uldbjerg N, de Graaf I, Thortnton JG, Bor P, Bakker JJH. Discontinuation of intravenous oxytocin in the active phase of induced labour. Cochrane Database Syst Rev. 2018; 8; 012274.

15. OMS (Organização Mundial da Saúde). As cesarianas devem ser realizadas somente quando clinicamente necessário Genebra; 2015.

16. Sandall J, Tribe RM, Avery L, Mola G, Visser GH, Homer CS, Gibbons D, Kelly NM, Kennedy HP, Kidanto H, Taylor $\mathrm{P}$, Temmerman M. Short and long-term effects of cesarean section on the health of women and children. Lancet. 2018; 392 (10155): 1349-57.

17. Kauffman E, Souter VL, Kanton JG, Sitcov K. Cervical dilation on admission in term spontaneous labor and maternal and newborn outcomes. Obstet Gynecol. 2016; 127 (3): 481-8

18. Oliveira LB, Mattos DV, Matão MEL, Martins CA. Perineal laceration associated with the use of exogenous. Rev Enferm UFPE on line. 2017; 11 (6): 2273-8. 
19. Andrade PON, Silva JQP, Diniz CMM, Caminha MFC. Fatores associados à violência obstétrica na assistência ao parto vaginal em uma maternidade de alta complexidade em Recife, Pernambuco. Rev Bras Saúde Mater Infant. 2016; 16 (1): 29-37.

20. Côrtes CT, Oliveira SMJV, Santos RCS, Francisco AA, Riesco MLG, Shimoda GT. Implementation of evidencebased practices in normal delivery care. Rev Latino Am Enferm. 2018; 26: e2988.

21. Medeiros RMK, Teixeira RC, Nicolini AB, Alvares AS, Corrêa ÁCP, Martins DP. Cuidados humanizados: a inserção de enfermeiras obstétricas em um hospital de ensino. Rev Bras Enferm. 2016; 69 (6): 1091-8.

22. Pearson A. Evidence synthesis and its role in evidencebased health care. Nurs Clin North Am. 2014; 49 (4): $453-$ 60 .

23. Ryan R, McCarthy F. Induction of labour. Obst Gynaecol Reprod Med. 2016; 26 (10): 304-10.

24. OMS (Organização Mundial da Saúde). Tecnologia apropriada para partos e nascimentos. Recomendações da Organização Mundial de Saúde. Maternidade Segura. Assistência ao parto normal: um guia prático. Genebra; 1996

Received on December 6, 2019

Final version presented on June 29, 2020

Approved on August 26, 2020
25. Schettini NJC, Griboski RA, Faustino AM. Partos normais assistidos por enfermeiras obstétricas: posição materna e a relação com lacerações perineais espontâneas. Rev Enferm UFPE on line. 2017; 11 (Supl. 2): 932-40.

26. Santosa RCS, Riesco MLG. Implementação de práticas assistenciais para prevenção e reparo do trauma perineal no parto. Rev Gaúcha Enferm. 2016; 37 (esp): e68304

27. Pato-Mosquera M, García-Lavandeira S, Liñayo-Chouza J. El desgarro intraparto del esfínter anali Puede prevenirse? Ginecol Obstet Mex. 2017; 85 (1): 13-20.

28. Kabiru WN, Jamieson D, Graves W, Lindsay M. Tendências de partos instrumentais em um hospital de ensino de cuidados terciários. Obstet Gynecol. 2015; 5 (7): 20-32.

29. Zenebe H, Ahadu W, Yibeltal S. Prevalence and Outcome of Operative Vaginal Delivery among Mothers Who Gave Birth at Jimma University Medical Center, Southwest Ethiopia. J Pregnancy. 2018; 7423475. 